\title{
ORIGINAL ARTICLE Elbow problems in paraplegic spinal cord injured patients: frequency and related risk factors-a preliminary controlled study
}

\author{
B Erhan ${ }^{1}$, B Gündüz ${ }^{1}$, AN Bardak ${ }^{1}, S$ Özcan ${ }^{1}$, A Çarlı ${ }^{2}$ H Er ${ }^{1}$, L Tekin ${ }^{2}$ and L Özçakar ${ }^{3}$
}

Study design: Cross-sectional controlled study.

Objectives: To evaluate the elbow joint with ultrasound in paraplegic patients, determine the related factors and compare it with healthy controls.

Setting: A training and research rehabilitation hospital in Istanbul.

Methods: A total of 30 paraplegic patients and 20 healthy controls were included in the study. Patients demographic data, pain in the elbow joint, level and duration of injury, ambulation status, type of wheelchair used, daily duration of wheelchair and other ambulation equipment usage, transfers being dependent or independent, daily number of push-ups were recorded. Elbow joints were evaluated with ultrasound for presence of fluid and thickness of the triceps tendon.

Results: Mean triceps tendon thickness values of the right side were larger in spinal cord injury (SCI) patients when compared with those of healthy controls'. Joint effusion on the right elbow joint was also found to be more common in $\mathrm{SCl}$ patients than in normal subjects. Triceps tendon thickness measurements were not found to be correlated with demographic and clinical factors. Seven paraplegic patients $(23 \%)$ reported that they have pain in the elbow.

Conclusion: In this preliminary study, our results showed that right elbow effusion was more frequent and right triceps tendon was thicker in $\mathrm{SCl}$ patients when compared with healthy subjects.

Spinal Cord (2013) 51, 406-408; doi:10.1038/sc.2013.13; published online 5 March 2013

Keywords: elbow effusion; musculoskeletal ultrasound; elbow pain; paraplegia; spinal cord injury; ambulation

\section{INTRODUCTION}

Among individuals with spinal cord injury (SCI), the prevalence of upper extremity (UE) problems is expected to be higher because SCI patients naturally rely on their UEs more than able-bodied individuals during daily activities, that is, ambulation, transfers and self care. In this regard, several studies have been performed in SCI patients and shoulder pain was found to be the most frequent problem in their UEs. ${ }^{1-4}$ On the other hand, although the elbow joint is also overused in SCI patients (for example, during push-up maneuvers), ${ }^{2}$ to our best notice, its relevant problems have not been explored in the hitherto literature.

Accordingly, the purpose of this study was twofold; first, we aimed to investigate elbow joint involvement in SCI patients. Herein, we reasoned that ultrasound-being a convenient diagnostic modality would be a prompt imaging alternative. ${ }^{5}$ Our second aim was to find out the difference of elbow joints with ultrasonographic evaluation between patients and healty controls and whether the ultrasonographic findings of their elbow joints correlated with any of the clinical features in SCI patients.

\section{MATERIALS AND METHODS}

The protocol of this cross-sectional trial was based on the Declaration of Helsinki and approved by the local ethics committee. All subjects were informed about the study procedure and written informed consent was obtained either from the patient or his/her representative. We certify that all applicable institutional and governmental regulations concerning the ethical use of human volunteers were followed during the course of this research.

\section{Participants}

Both elbows of the 30 patients with paraplegia (23 males (M), 7 females (F)) and 20 healthy controls ( $11 \mathrm{M}, 9 \mathrm{~F}$ ) were evaluated in the study. Age range was between 20 and 70 years. Subjects with disease duration of less than 3 months or those with a previous elbow surgery, trauma or rheumatic disease were excluded. Demographic and clinical data including age, gender, body mass index (BMI), level and duration of SCI, ambulation status (wheelcahir, walking aid), daily number of transfer and push-up activities, wheelchair type and duration of daily wheelchair use and walking aid use were noted; patients were divided into two groups as dependent and independent according to their transfer status.

\section{Ultrasonographic evaluation}

A 12-MHz linear probe (Logiq P5, GE Medical Systems, Milwaukee, WI, USA) was used for all the evaluations. Subjects were seated while elbow joints were evaluated for the presence of fluid (humeroradial and humeroulnar joints anteriorly and olecranon fossa posteriorly). Triceps tendon thickness (TTT)

${ }^{1}$ Department of Physical Medicine and Rehabilitation, Istanbul Physical Medicine and Rehabilitation Training Hospital, Istanbul, Turkey; ${ }^{2}$ Department of Physical Medicine and Rehabilitation, Haydarpaşa Training Hospital, Gülhane Military Medical Academy, Istanbul, Turkey and ${ }^{3}$ Department of Physical Medicine and Rehabilitation, Hacettepe University Medical School, Ankara, Turkey

Correspondence: B Erhan, Department of Physical Medicine and Rehabilitation, Istanbul Physical Medicine and Rehabilitation Research and Training Hospital, Istanbul 34180 Turkey.

E-mail: dr.belginerhan@gmail.com

Received 30 August 2012; revised 19 December 2012; accepted 1 February 2013; published online 5 March 2013 
measurements were performed axially. Other pathologies of the elbow joint or the surrounding soft tissues (edema, bursitis, and so on) were noted if present.

\section{Statistical analysis}

Statistical analysis was done by using SPSS version 15.0. Mean \pm s.d. and median $(\min -\max )$ values were used as descriptive statistics. Mann-Whitney $\mathrm{U}$ - and $\chi^{2}$ tests were used for group comparisons of patients and healthy controls, gender, dexterity of the patients, ambulation device groups, transferdependent and -independent patients. Pearson rank coefficients were used to explore correlations between ultrasonographic measurements and clinical features of the subjects. Statistical significance level was set at $P<0.05$.

\section{RESULTS}

Demographic and clinical features of the subjects are given in Table 1. Both groups were similar with respect to age, gender, dexterity and BMI. A total of 25 (83\%) SCI patients were using manual wheelchair; 18 of these wheelchair using patients were also ambulating with walking aids such as walker or crutches; 5 patients were ambulating with walking aids. In all, 7 (23\%) patients were dependent for transfers, whereas $23(67 \%)$ patients were independent. Median (min-max) daily values for duration of wheelchair use, frequency of transfers and push-up counts were $6(1-14)$ h, 6 (2-23) times per day and 17 (1-60), respectively. Seven patients had elbow pain, five of them being bilateral and two being on the left side (Table 2).

Ultrasonographic findings pertaining to 60 (SCI) vs 40 (normal) elbow joints are shown in Table 3. Mean TTT (right side) values were larger in SCI patients when compared with those of healthy controls'. Joint effusion (right side) was found to be more common in SCI patients than normal subjects. TTT measurements were not found to be correlated with age, gender, duration of injury, transfer/push-ups, wheelchair or walking aid use (Table 4). Two patients with elbow pain had fluid in their both elbows.

Right TTT was positively correlated with BMI, whereas there was no correlation between tendon thickness and age, duration of injury, wheelchair or walking aid use, frequency of transfers or push-ups (Table 5).

Table 1 Demographic and clinical features of the subjects

\begin{tabular}{|c|c|c|c|}
\hline & $\mathrm{SCl}$ & Control & P-value \\
\hline & $(\mathrm{N}=30)$ & $(N=20)$ & \\
\hline Female/male & $7 / 23$ & $9 / 11$ & 0.131 \\
\hline Age (years) & $34.37 \pm 12.12$ & $43.85 \pm 11.14$ & 0.768 \\
\hline BMI $\left(\mathrm{kg} \mathrm{m}^{-2}\right)$ & $25.62 \pm 4.01$ & $27.70 \pm 5.87$ & 0.134 \\
\hline $\begin{array}{l}\text { Dominant extremity } \\
\text { (right/left) }\end{array}$ & $26 / 4$ & $20 / 0$ & 0.140 \\
\hline $\mathrm{SCl}$ duration (months) & $91.28 \pm 82.86$ & & \\
\hline Median (range) & $66(3-360)$ & & \\
\hline \multicolumn{4}{|l|}{ SCl level, N (\%) } \\
\hline Thoracic & $22(74 \%)$ & & \\
\hline Lumbar & $8(26 \%)$ & & \\
\hline \multicolumn{4}{|l|}{ SCI AIS grade, $\mathrm{N}$} \\
\hline A & 18 & & \\
\hline$B$ & 6 & & \\
\hline C & 3 & & \\
\hline $\mathrm{D}$ & 3 & & \\
\hline
\end{tabular}

Abbreviations: AIS, ASIA Impairment Scale; BMI, body mass index; SCI, spinal cord injury.

\section{DISCUSSION}

In this study, we tried to evaluate the elbow joints of SCI patients by using ultrasonography. Our results have shown that right elbow effusion was more frequent and right triceps tendon was thicker in SCI patients when compared with healthy subjects.

After SCI, paraplegic patients use their upper limbs during several weight-bearing activities during the day. Accordingly, the upper limb joints and the nearby soft tissues may be expected to undergo overuse type of injuries. Further, tendons are force-transmitting units of the

Table 2 Demographic and clinical factors of $\mathrm{SCl}$ patients with elbow pain

\begin{tabular}{|c|c|c|c|c|c|c|c|}
\hline Patient & Gender & $\begin{array}{l}\text { Injury } \\
\text { level }\end{array}$ & $\begin{array}{c}\text { Affected } \\
\text { side }\end{array}$ & AIS & $\begin{array}{l}\text { Duration of } \\
\text { wheelcair or } \\
\text { walking aid use } \\
\text { (hours per day) }\end{array}$ & $\begin{array}{c}\text { Number of } \\
\text { push-ups } \\
\text { per day }\end{array}$ & $\begin{array}{c}\text { Number of } \\
\text { transfers } \\
\text { per day }\end{array}$ \\
\hline 1 & M & $\mathrm{T} 11$ & B & A & 11 & 30 & 20 \\
\hline 2 & $M$ & L2 & B & B & 3 & 6 & 4 \\
\hline 3 & M & T10 & $B$ & $D$ & 4 & 60 & 10 \\
\hline 4 & $\mathrm{~F}$ & L1 & $\mathrm{L}$ & B & 4 & 20 & 6 \\
\hline 5 & $M$ & T6 & B & $A$ & 5 & 3 & 6 \\
\hline 6 & $\mathrm{~F}$ & L2 & $\mathrm{L}$ & $B$ & 4 & 20 & 2 \\
\hline 7 & $M$ & $\mathrm{~T} 4$ & B & $A$ & 14 & 20 & 10 \\
\hline
\end{tabular}

Abbreviations: AIS, ASIA Impairment Scale, B, bilateral; F, female; L, left; M, male; SCI, spinal cord injury.

Table 3 Ultrasonographic findings of the elbow joint

\begin{tabular}{lccr}
\hline & SCl & Control & P-value \\
\hline Right TTT $(\mathrm{cm})$ & $0.407 \pm 0.065$ & $0.365 \pm 0.066$ & 0.032 \\
Left TTT $(\mathrm{cm})$ & $0.408 \pm 0.069$ & $0.371 \pm 0.632$ & 0.059 \\
Effusion, RE $(n(\%))$ & $14(46.7)$ & $4(20)$ & 0.032 \\
Effusion, LE $(n(\%))$ & $12(40)$ & $4(20)$ & 0.216
\end{tabular}

Abbreviations: LE, left elbow; RE, right elbow; $\mathrm{SCl}$, spinal cord injury; TTT, triceps tendon thickness.

$P<0.05$ is shown in bold.

Table 4 The association of triceps tendon thickness with gender, transfer dependency, wheelchair and walking aid use

\begin{tabular}{|c|c|c|c|c|}
\hline & Right TTT (cm) & $\mathrm{P}$-value & Left TTT $(\mathrm{cm})$ & $\mathrm{P}$-value \\
\hline \multicolumn{5}{|l|}{ Gender } \\
\hline Female & $0.412 \pm 0.068$ & 0.417 & $0.406 \pm 0.068$ & 0.694 \\
\hline Male & $0.388 \pm 0.584$ & & $0.366 \pm 0.064$ & \\
\hline \multicolumn{5}{|c|}{ Transfer dependency } \\
\hline Dependent & $0.398 \pm 0.065$ & 0.749 & $0.394 \pm 0.047$ & 0.606 \\
\hline Independent & $0.409 \pm 0.067$ & & $0.375 \pm 0.015$ & \\
\hline \multicolumn{5}{|l|}{ Wheelchair use } \\
\hline Yes & $0.406 \pm 0.069$ & 0.867 & $0.406 \pm 0.072$ & 0.435 \\
\hline No & $0.408 \pm 0.050$ & & $0.416 \pm 0.049$ & \\
\hline \multicolumn{5}{|l|}{ Walking aid use } \\
\hline Yes & $0.412 \pm 0.068$ & 0.685 & $0.410 \pm 0.081$ & 0.702 \\
\hline No & $0.401 \pm 0.066$ & & $0.410 \pm 0.050$ & \\
\hline
\end{tabular}

Abbreviation: TTT, thickness of the triceps tendon. 
Table 5 The correlation between tendon thickness measurements, demographic and clinical data

\begin{tabular}{|c|c|c|c|c|}
\hline & Right TTT & Left TTT & & \\
\hline & r-value & P-value & r-value & P-value \\
\hline Age & 0.229 & 0.224 & 0.229 & 0.224 \\
\hline BMI & 0.370 & 0.044 & 0.283 & 0.129 \\
\hline Duration of injury & -0.225 & 0.232 & -0.235 & 0.232 \\
\hline Duration of wheelchair use & -0.209 & 0.267 & -0.209 & 0.267 \\
\hline Duration of walking aid use & -0.218 & 0.356 & -0.160 & 0.502 \\
\hline Frequency of transfers & 0.216 & 0.290 & 0.405 & 0.171 \\
\hline Frequency of push-ups & -0.008 & 0.970 & -0.115 & 0.575 \\
\hline
\end{tabular}

Abbreviations: TTT, thickness of the triceps tendon; BMI, body mass index.

$P<0.05$ is shown in bold.

musculoskeletal system and due to their low metabolic rate and slow healing, chronic overuse injury may cause structural changes and impact on tendons and peripheral soft tissues. ${ }^{6}$ During weight-relief lifting activities, high-to-moderate muscular demands were documented on long head of triceps muscle besides latissimus dorsi and sternal pectoralis muscle. ${ }^{7,8}$ Although previous reports have explored shoulder injuries in SCI, ${ }^{3,9-12}$ the elbow joint, which serves as one of the main biomechanical units during the daily activities of paraplegic patients, has not been substantially evaluated in the relevant literature. In this regard, we believe that our first and preliminary results, of increased TTT and frequency of joint fluid, are noteworthy. Additionally, we attribute the fact that these differences are on the right side to the distribution of UE dominance in our study group.

Several demographical and clinical factors may affect the joints, tendons and peripheral neurons of patients who overuse their extremities. $^{6}$ Dudley-Javoroski et al., ${ }^{13}$ showed the effect of the increasing weight among SCI patients on the achilles tendon in a controlled study with normal population. We found relationship between BMI and the right tendon thickness; this can be explained by the increase of TTT with the increasing BMI, similar to the previous literature. Van Drongelen et al. ${ }^{14}$ have investigated the acute changes in the biceps tendon after a high-intensity wheelchair propulsion activity in 42 basketball and quad rugby players using ultrasonography. An increase in fluid content of biceps tendon was shown, which increased as the duration of playing time increased showing a link between activity level and acute tendon changes. This association is probably more profound in high-intensity activities.

There are limited data on the prevalence of elbow pain in paraplegic patients; in this small group of SCI patients, the prevalence was 7 out of $30(23 \%)$. Although the patient characteristics was different (older age, longer injury duration, paraplegic and tetraplegic patients investigated together), the prevalence was found to be $35 \%$ in a study by Dalyan et al. ${ }^{4}$ The prevalence is reported as $6-15 \%$ in other studies. ${ }^{15}$ Although the prevalence differs among the studies, the elbow pain affects $\sim 1$ out of 4-6 patients and more emphasis should be given on causes and preventive measures.

Our study has some strengths and limitations. The strength of our study is that, it is the first study about the ultrasonographic evaluation of elbow joint in SCI patients. The major limitation of our study is the limited number of patients. Further studies should be performed with larger groups of patients investigating other factors, such as job, exercise duration, type of wheelchair or other daily living activities, which might affect the elbow joint.

\section{DATA ARCHIVING}

There were no data to deposit.

\section{CONFLICT OF INTEREST}

The authors declare no conflict of interest.

1 Gironda RJ, Clark ME, Neugaard B, Nelson A. Upper limb pain in a national sample of veterans with paraplegia. J Spinal Cord Med 2004; 27: 120-127.

2 Gianini PES, Chamlian TR, Arakaki JC. Shoulder pain in spinal cord injury. Acta Ortop Bras 2006; 14: 44-47.

3 Brose SW, Boninger ML, Fullerton B, McCann T, Collinger JL, Impink BG et al Shoulder ultrasound abnormalities, physical examination findings, and pain in manual wheelchair users with spinal cord injury. Arch Phys Med Rehabil 2008; 89: 2086-2093.

4 Dalyan M, Cardenas DD, Gerard B. Upper extremity pain after spinal cord injury. Spinal Cord 1999; 37: 191-195.

5 Özçakar L, Tok F, DeMuynck M, Vanderstraeten G. Musculoskeletal ultrasonography in physical and rehabilitation medicine. J Rehabil Med 2012; 44: 310-318.

6 Özçakar L, Kömürcü E, Safaz I, Göktepe AS, Yazicioğlu K. Evaluation of the patellar tendon in transtibial amputees: a preliminary sonographic study. Prosthet Orthot Int 2009; 33: 324-328.

7 Gagnon D, Nadeau S, Gravel D, Noreau L, Lariviére C, McFadyen B. Movement patterns and muscular demands during posterior transferstoward an elevated surface in individuals with spinal cord injury. Spinal Cord 2005; 43: 74-84.

8 Reyes ML, Gronley JK, Newsam CJ, Mulroy SJ, Perry J. Electromyographic analysis of shoulder muscles of men with low-level paraplegia during a weight relief raise. Arch Phys Med Rehabil 1995; 76: 433-439.

9 Nawoczensk DA, Riek LM, Greco L, Staiti K, Ludewig PM. Effect of shoulder pain on shoulder kinematics during weight bearing tasks in persons with spinal cord injury. Arch Phys Med Rehabil 2012; 5: 2.

10 Samuelsson KA, Tropp H, Gerdle B. Shoulder pain and its consequences in paraplegic spinal cord-injured, wheelchair users. Spinal Cord 2004; 42: 41-46.

11 Alm M, Saraste H, Norrbrink C. Shoulder pain in persons with thoracic spinal cord injury: prevalence and characteristics. J Rehabil Med 2008; 40: 277-283.

12 Dyson-Hudson TA, Kirshblum SC. Shoulder pain in chronic spinal cord injury, Part I: Epidemiology, etiology, and pathomechanics. J Spinal Cord Med 2004; 27: 4-17.

13 Dudley-Javoroski S, McMullen T, Borgwardt MR, Peranich LM, Shields RK. Reliability and responsiveness of musculoskeletal ultrasound in subjects with and without spinal cord injury. Ultrasound Med Biol 2010; 36: 1594-1607.

14 Van Drongelen S, De Groot S, Veeger HE, Angenot EL, Dallmeijer AJ, Post MW et al. Upper extremity musculoskeletal pain during and after rehabilitation in wheelchairusing persons with a spinal cord injury. Spinal Cord 2006; 44: 152-159.

15 Boninger ML, Collinger JL, Cooper RA, Koontz AM. Musculoskeletal pain and overuse injuries. In: Lin VW ED.Spinal Cord Medicine: Principles and Practice, 2nd edn Demos Medical: New York, 2010, pp p627-p635. 